\title{
O monolinguismo nacionalista do estado novo nas páginas da Revista de Imigração e Colonização
}

\section{Pedrina Barros de Castro ${ }^{1}$}

Resumo: Este trabalho tem como objetivo analisar a contribuição da Revista de Imigração e Colonização ao conjunto de ações implementadas pelo Governo Vargas no período do Estado Novo (1937-1945) de forma a disseminar e legitimar o nacionalismo no Brasil. Nesse contexto, a defesa do monolinguismo baseado na língua portuguesa era entendida como fundamental para se alcançar não só a união da população brasileira como a assimilação das comunidades de imigrantes. Dessa maneira, além das políticas autoritárias de restrição ao uso e ao aprendizado do idioma estrangeiro, realizadas diretamente pelo Governo Vargas por meio de leis, diversas outras políticas linguísticas foram desenvolvidas mediante a utilização do aparato estatal, com o objetivo de construção da identidade nacional, como a publicação da Revista de Imigração e Colonização.

Palavras-chave: Políticas linguísticas. Nacionalismo. Revista de Imigração e Colonização.

nacionalismo representou um dos principais alicerces do primeiro governo de Getúlio Vargas (1930-1945), perpassando os mais diversos âmbitos de atuação, como econômico, político, social, cultural e de segurança. Atuando como elemento aglutinador no projeto de desenvolvimento do Brasil, o ideário nacionalista se acentuou durante a ditadura do Estado Novo (1937-1945).

A crise mundial do liberalismo, decorrente, principalmente, dos problemas sociais e políticos sobrevindos da primeira Guerra Mundial na Europa, bem como dos problemas econômicos que culminaram na quebra

1 Possui graduação em Letras: Português/Literaturas pela Universidade Federal Fluminense (2004) e mestrado em Linguística Aplicada ao Ensino de Português para Estrangeiros pela mesma Universidade (2006). É doutoranda em História, Política e Contato Linguístico no Programa de Pós-Graduação em Estudos da Linguagem da Universidade Federal Fluminense. 
da Bolsa de Valores de Nova Iorque, em 1929, concorreu para o surgimento de sistemas políticos totalitários, como o fascismo e o nazismo, bem como para a defesa de uma maior intervenção do Estado na economia.

No Brasil, a Revolução de 1930, que deu fim à alternância de poder entre as oligarquias agrárias dos estados de São Paulo e Minas Gerais, inaugurou um novo tempo - a Era Vargas (1930-1945). Os 15 anos do presidente Getúlio Vargas no poder federal foram marcados por muitas disputas políticas. Alianças e rivalidades entre os principais grupos políticos em cena se alternavam, conforme se apresentava o complexo cenário político e econômico do país. O próprio Presidente se transmutou ao longo dos anos, traçando caminhos e aproveitando oportunidades na construção do seu projeto de poder. De líder do movimento que derrubou a República Velha e instituiu o Governo Provisório (1930-1934), passando pela incipiente democratização do país no Governo Constitucional (19341937) e chegando, enfim, a seu objetivo, o Estado Novo (1937-1945), Vargas apresentou uma trajetória que, embora oscilante e muitas vezes até contraditória, foi marcada pela busca da centralização do poder em sua figura.

Admirador do regime fascista de Mussolini na Itália, Vargas acreditava que a democracia liberal era um entrave à solução dos problemas pelos quais o Brasil passava, não sendo possível a realização das profundas mudanças necessárias ao desenvolvimento do país, senão por meio de um Estado forte e centralizado. Da mesma maneira, entendia que somente por meio da concentração do poder no Estado seria possível a coesão nacional e o alcance do bem comum. Nesse contexto, foram criadas estruturas burocráticas de administração e planejamento, consolidando, assim, o intervencionismo estatal. Segundo Belarmino,

Em diferentes setores sociais, órgãos ligados diretamente à presidência ou aos ministérios funcionavam como aparatos legais das políticas 
implantadas pelo Estado Novo. Eram transmissores do discurso nacionalista que buscava alcançar os diversos grupos sociais existentes (BELARMINO, 2012, p. 60).

Entre esses órgãos, encontrava-se o Conselho de Imigração e Colonização, criado em 1938, quando houve uma redefinição da política imigratória do Brasil, que se refletiu em uma ampla legislação sobre o assunto. A questão das comunidades de imigrantes era tratada com muita atenção pelo Governo, uma vez que o projeto de construção da Nação preconizava a homogeneização da população - um só povo, uma só língua, uma só nação.

Monteagudo (2012) explica que, com a invenção do nacionalismo, decorrente das mudanças revolucionárias ocorridas na Europa a partir do séc. XVIII, tornou-se norma o monolinguismo dos Estados. Segundo o autor,

[...] a nação devia ter uma cultura homogênea exprimida numa língua comum. Da noção de "estado francês" (que correspondia ao velho estado dinástico, multi-étnico e plurilíngue) passou-se à noção de "nação francesa", e essa nação devia se exprimir na única língua nacional, a língua francesa (MONTEAGUDO, 2012, p. 48).

Desde então, o plurilinguismo, que era o natural nos estados dinásticos, passou a ser considerado a exceção e até mesmo uma anomalia nos estados-nação, devendo ser substituído pelo monolinguismo. Assim, entendendo-se a língua como ferramenta de transmissão de valores e crenças, como fator de identidade, de pertença, a diversidade linguística representava uma ameaça à nação brasileira. Dessa maneira, fazia-se fundamental a assimilação dos imigrantes, principalmente das colônias mais afastadas, situadas nas zonas rurais da região sul do país. A existência 
dessas áreas, chamadas de quistos raciais, onde comunidades viviam a cultura de seu país de origem, fechadas à sociedade externa a elas, era vista com apreensão pelo Estado.

Nesse propósito de assimilação das comunidades de imigrantes, foram desenvolvidas políticas linguísticas, visando a assegurar o monolinguismo nacionalista do Estado Novo. Assim, a língua se constituiu num poderoso instrumento de coerção, não só na obrigação do aprendizado e do uso do português, como na proibição do aprendizado e do uso do idioma do imigrante. Para que essas políticas fossem bem sucedidas, o Governo Vargas fazia uso tanto do aparelho repressivo do Estado - como legislação e exército - quanto do aparato ideológico - como meios de comunicação e intelectuais.

A partir de 1938, foi construído um rígido arcabouço jurídico em torno da questão imigratória que impunha inúmeras restrições às comunidades de imigrantes, a começar pelo Decreto-Lei no 406/1938. Nele foram estabelecidos os preceitos para a entrada e permanência dos estrangeiros no país, a quem foram negados direitos linguísticos como: denominar em idioma estrangeiro qualquer núcleo, centro ou colônia, além de estabelecimentos de comércio, indústrias e associações; e, nas escolas rurais, ministrar em língua estrangeira qualquer matéria, bem como ensinar idioma estrangeiro a menores de 14 anos e utilizar, no ensino primário, livros escritos em idioma estrangeiro.

Outras normas decretadas no mesmo ano e no seguinte dão continuidade ao exercício do poder de polícia linguística. O Decreto $\mathrm{n}^{\circ}$ 3.010/1938 sujeita a publicação de material impresso em língua estrangeira a autorização e registro no Ministério da Justiça. E nas zonas rurais, fazse necessária ainda consulta prévia e parecer favorável do Conselho de Imigração e Colonização, tendo em vista "a necessidade de impedir o cultivo demasiadamente vivo da língua, de tradições e costumes estrangeiros numa determinada zona” (BRASIL, 1938b). O Decreto-Lei no 868/1938, 
que cria a Comissão Nacional de Ensino Primário, dá início à Campanha de Nacionalização do Ensino, cujo objetivo principal era a nacionalização integral das chamadas escolas étnicas, criadas pelos imigrantes nas áreas rurais do país.

Por fim, o Decreto-Lei no 1.545/1939, que dispunha sobre a adaptação ao meio nacional dos brasileiros descendentes de estrangeiros, determinava as competências dos principais órgãos públicos federais no projeto de assimilação dos imigrantes. Conforme o Art. 10: "Essa adaptação far-se-á pelo ensino e pelo uso da língua nacional, pelo cultivo da história do Brasil, pela incorporação em associações de caráter patriótico e por todos os meios que possam contribuir para a formação de uma conciência comum" (BRASIL, 1939b). ${ }^{2}$

Para dar legitimidade a todo esse aparato repressivo, o Governo Vargas contou com o apoio de parte significativa da intelectualidade da época, além dos meios de comunicação privados, mas, acima de tudo, valeu-se das instituições do próprio Estado, como o Conselho de Imigração e Colonização.

Segundo Cooper (1997, p. 98), mesmo em governos totalitários, o consentimento dos governados é fundamental para que uma política linguística seja bem-sucedida. Dessa maneira, antes de sua implementação, é importante a realização de ações de promoção das políticas linguísticas com o objetivo de se criar uma opinião pública positiva sobre elas.

Nesse sentido, o Conselho de Imigração e Colonização assume um papel de destaque, principalmente por meio da publicação da Revista de Imigração e Colonização, na construção de um discurso de legitimação das políticas linguísticas opressivas do Estado Novo.

2 Foi mantida a ortografia original nas citações retiradas tanto da legislação pesquisada quanto da Revista de Imigração e Colonização. 


\section{O Consellho de Imigração e Colonização}

O Conselho de Imigração e Colonização (CIC) foi criado em 4 de maio de 1938 pelo já citado Decreto-Lei no 406, que dispunha sobre a entrada de estrangeiros no território nacional. Sua principal função era coordenar as ações relacionadas com a imigração, a colonização e a concentração de estrangeiros no país. ${ }^{3}$

Composto por sete membros nomeados pelo Presidente da República, o órgão contava ainda com a participação de representantes dos estados da federação, que atuavam como observadores. Havia uma grande interlocução entre o CIC e os interventores federais nos estados. De um lado, o Conselho realizava, a pedido destes, pesquisas para verificar o nível de assimilação das comunidades imigrantes, fornecendo informações acerca das vantagens e desvantagens em receber imigrantes de determinada procedência. Do outro, os representantes dos estados contribuíam com informações obtidas por meio da experiência direta com as comunidades de imigrantes nos estados.

As competências do CIC, arroladas em seu regimento interno (Decreto $\mathrm{n}^{\circ}$ 3.691/1939), dividem-se em duas grandes vertentes: a da proposição ao Governo de medidas legais referentes a questões como fixar cotas de imigração e fiscalizar a sua distribuição, promover a assimilação e evitar a concentração de imigrantes em qualquer ponto do território nacional, proibir total ou parcialmente a imigração, reformar os serviços imigratórios etc.; e a da realização de estudos referentes a questões como os problemas relativos à seleção imigratória, à antropologia étnica e social, à biologia racial e à eugenia, os movimentos imigratórios, a colonização em geral etc.

3 Ao Conselho também competiam estudos e planejamentos referentes a temas como migração interna, vazios demográficos, questões agrárias e turismo. 
Durante o Estado Novo, consolidou-se a noção de que era indispensável um maior controle sobre todo o processo imigratório. Entendia-se como fundamental para o crescimento do país aumentar o seu contingente populacional e, para o Conselho, o papel do imigrante permanecia essencial. No entanto, já não era mais possível uma imigração indiscriminada. Criou-se então a figura do imigrante desejado, aquele que deveria preencher os requisitos estabelecidos de forma a servir aos interesses do país.

As ações desenvolvidas no primeiro ano de trabalho do CIC foram apresentadas num artigo no primeiro número da Revista de Imigração e Colonização, órgão oficial do Conselho. Nele, também foram expostos os princípios da política imigratória do Estado Novo.

Para os países novos como o Brasil, a política imigratória que mais convém é a que tem em vista evitar os elementos indesejáveis e os de difícil assimilação, e promover a entrada de boas correntes imigratórias em harmonia com a expansão econômica do país. Essa política tem de basear-se, portanto, no selecionamento da imigração, pois é dever máximo do Estado intervir na composição da sua população, de forma a criar a maior colaboração e harmonia entre os elementos que a formam (CONSELHO, 1940, p. 7).

Para além das questões econômicas, outro ponto importante da política imigratória era a formação da nacionalidade. Dessa maneira, deveria ser dada especial atenção à escolha dos imigrantes, levando-se em consideração a possibilidade de assimilação destes, de forma a se atingir a homogeneidade da população brasileira. No mesmo artigo, temos os fatores considerados como favoráveis e desfavoráveis à assimilação:

Entre os fatores favoráveis à assimilação estão a afinidade étnica, a imigração familiar, os esforços do 
Estado no sentido de facilitar a adaptação do elemento estrangeiro, a igualdade econômica e social entre os trabalhadores nacionais e estrangeiros, os casamentos mixtos e a religião. Entre os fatores que se opõem à assimilação citam-se os obstáculos erigidos pelo país de origem, a segregação, as diferenças de línguas, o serviço militar no país estrangeiro e as diferenças étnicas muito salientes (CONSELHO, 1940, p. 7-8).

Observa-se, ao longo do artigo, a preocupação do Conselho com a formação de um discurso de defesa dos interesses da Nação, fundamentado em estudos e pesquisas, diálogos com especialistas, e decorrente de consultas provenientes de autoridades e até mesmo de particulares. Para Belarmino, “[...] se faz necessário situar o Conselho de Imigração e Colonização em um contexto de produção intelectual que servia como instrumento de um Estado que se propunha a realizar mudanças nas mais diversas áreas da sociedade brasileira" (BELARMINO, 2012, p. 4).

Assim, além de controle e fiscalização dos movimentos migratórios, o Órgão também funcionava como mecanismo de disseminação da política nacionalista do Governo por meio de incursões ao interior, participação em eventos e publicação da Revista de Imigração e Colonização.

\section{A Revista de Imigração e Colonização}

Nesta pesquisa, foram examinadas 18 edições da Revista de Imigração e Colonização ${ }^{4}$ (RIC), publicadas, em sua maioria, trimestralmente, de janeiro de 1940 a maio-setembro de 1945.

A Revista foi criada com o propósito de fornecer informações relacionadas com imigração e colonização no Brasil. Conforme explica, em

4 Todas baixadas no site da Biblioteca Digital Seade. https://bibliotecadigital.seade.gov.br/view/index.php\#4. Acesso em: 06 maio 2020. 
sua primeira edição, o Presidente do Conselho de Imigração e Colonização, João Carlos Muniz, a Revista tinha como objetivo:

[...] servir de elemento de coordenação entre os que se preocupam no Brasil com os problemas demográficos, animando e orientando as pesquisas nesses assuntos e contribuindo, ao mesmo tempo, para criar na opinião do país uma melhor compreensão dêsses problemas (MUNIZ, 1940, p. 4).

A RIC praticamente não sofreu alterações em sua estrutura ao longo dos anos, sendo composta basicamente por artigos, noticiário, legislação nacional e resoluções/pareceres do CIC. Os artigos eram escritos, em sua grande maioria, pelos próprios conselheiros, mas também eram convidados a contribuir para a Revista funcionários de outros órgãos do governo brasileiro, bem como de governos estrangeiros, interventores dos estados da federação, intelectuais e técnicos (inclusive imigrantes alemães e italianos) em áreas como agronomia, sociologia, engenharia, estatística etc. Segundo Queiroz,

De maneira geral, colaboraram com as publicações da revista com artigos, pareceres ou relatórios: médicos, psiquiatras, higienistas, jornalistas, juristas, educadores e diplomatas. Homens que em sua maioria ocuparam cargos importantes no Estado Novo e que principalmente após a mudança na atuação do intelectual "homens de pensamento e ação", encontraram espaço para a divulgação de seus ideais (QUEIROZ, 2013, p. 145).

Os artigos versavam sobre demografia, entrada e registro de estrangeiros, antropologia, núcleos coloniais e imigração nos estados da federação etc. A partir de 1942, houve uma diminuição na quantidade de artigos por edição e foram acrescentadas outras seções como "documentos 
históricos", "livros e revistas" (com sugestões) e "estatística" (sobre registro de estrangeiros por estado do país).

As cinco primeiras edições da Revista possuem um resumo em francês de cada um dos artigos publicados, encerrando-se essa prática apenas na sexta edição, nos números 2 e 3 de 1941. O uso do idioma francês, que na época era a língua da diplomacia e de alto prestígio entre os intelectuais, tinha como objetivo alcançar missões diplomáticas estrangeiras e outras instituições internacionais. Esse fato linguístico também comprova que, para o Governo Vargas, o problema não residia no uso de qualquer idioma estrangeiro, nem mesmo no idioma estrangeiro em si, mas no uso que se fazia dele e quem o fazia.

A circulação da RIC se dava não só nos organismos oficiais e culturais brasileiros, como também eram enviados exemplares a diversas empresas particulares. A criação da Revista e a publicação de seu primeiro número foram divulgadas amplamente na mídia brasileira, em jornais como Diário de Notícias, Jornal do Comércio, Jornal do Brasil, O Globo, entre outros.

A cada novo ano era publicado, na primeira edição da Revista, um relatório das atividades realizadas pelo Conselho no ano anterior. Conforme os cinco relatórios apresentados, de 1940 a 1944, a Segunda Guerra Mundial afetou gravemente o fluxo migratório da Europa para o Brasil, tornando as atividades do CIC de caráter meramente legislativo e teórico. Assim, nesse período, o Conselho respondeu consultas a ele encaminhadas, elaborou pareceres, tratou de casos omissos na legislação, realizou estudos e empreendeu viagens de inspeção nos núcleos coloniais. O Conselho acreditava estar se preparando de forma racional e planejada para "um grande surto migratório" (CONSELHO, 1942, p. 12) que acometeria o Brasil com o término da guerra.

$\mathrm{Na}$ RIC, podemos observar duas preocupações principais do Conselho: a entrada de estrangeiros no país e as colônias de imigrantes nele já estabelecidas. Apesar de os relatórios anuais apontarem a guerra 
como responsável pela impossibilidade de o Conselho planejar a migração coletiva europeia ao Brasil, havia disputas de poder pelo comando da política imigratória no interior do Governo Vargas e correntes de pensamento distintas, o que na prática cerceava as ações do CIC.

Segundo Koifman (2012, p. 173-174), as questões relacionadas com imigração diziam respeito pincipalmente aos ministérios do Trabalho, Indústria e Comércio (MTIC), das Relações Exteriores (MRE) e da Justiça e Negócios Interiores (MJNI). No entanto, a partir do Decreto-Lei $\mathrm{n}^{\mathrm{o}} 3.175 / 1941$ (que restringia a imigração), o controle sobre a entrada e a permanência de estrangeiros no país passou quase exclusivamente ao MJNI, do ministro Francisco Campos.

Campos discordava do ponto de vista do Conselho de que os imigrantes eram importantes para o crescimento do país e se valia de uma frase dita em discurso pelo próprio presidente Vargas: "O Brasil terá de ser povoado, desbravado e cultivado pelos brasileiros" (KOIFMAN, 2012, p. 82). Para o Ministro, a entrada de estrangeiros no país não era uma questão de cunho econômico, mas sim uma questão de polícia e de ordem pública. Entendia ainda que a migração europeia ao Brasil, no decorrer da guerra, deveria ser evitada, por se tratar de refugiados, que nada teriam a contribuir para o país.

Vargas, contudo, apoiava sobremaneira a imigração portuguesa, por representar a principal base de composição do povo brasileiro e compartilhar da mesma religião, cultura e língua, favorecendo, assim, o projeto de homogeneização da população brasileira.

Para Koifman,

[...] o governo viveu o paradoxo de manter-se muito interessado em "atrair novas levas imigratórias", desde que previamente selecionadas, e, por outro lado, muito aplicado em restringir ao máximo possível a entrada de imigrantes considerados indesejáveis (KOIFMAN, 2012, p. 43). 
Diante das dificuldades na orquestração dos fluxos migratórios coletivos europeus, o CIC voltou sua atenção ao projeto de assimilação das comunidades de imigrantes já fixadas no Brasil havia gerações, e utilizou a Revista para criar e difundir a mística da pátria.

Com o objetivo de validar seu discurso nacionalista e xenófobo, o Conselho buscava demonstrar amplo conhecimento no assunto. Assim, a Revista dava voz a técnicos e especialistas na área, bem como utilizava dados estatísticos sobre a imigração no Brasil, defendia o registro de estrangeiros e promovia exaustivamente o censo nacional.

No entanto, era nos artigos dos conselheiros que a defesa da assimilação das comunidades de imigrantes mais se acentuava. Chamam especial atenção dois artigos do conselheiro Major Aristóteles de Lima Câmara: "Os alemães no sul do Brasil (ponto de vista brasileiro)" (CÂMARA, 1940a, p. 33-46), em contraposição a um artigo de Reinhard Maack (alemão que vivia no Brasil) sobre a colonização alemã no sul do país; e "A nacionalização do ensino" (CÂMARA, 1940b, p. 236-253), reprodução da conferência realizada por Câmara, no primeiro curso de férias da Associação Brasileira de Educação ${ }^{5}$.

O primeiro artigo tinha como objetivo desfazer dois pressupostos: de que nos núcleos de colonização alemã havia o sentimento de pertencimento ao país de origem, com o cultivo de sua cultura e língua, em detrimento do país de acolhimento; e de que o Governo federal impunha a assimilação dessa população.

Para legitimar seus argumentos, Câmara utiliza tanto o seu testemunho pessoal, uma vez que estabeleceu contato direto com os colonos nas incursões às comunidades, quanto o depoimento dos próprios imigrantes. Segundo ele, os alemães que viviam no Brasil não gostavam

5 Fundada em 16 de outubro de 1924 por Heitor Lyra da Silva, junto a outros importantes intelectuais e educadores da época, a Associação Brasileira de Educação foi um dos principais espaços de discussão sobre a educação nacional na primeira metade do século XX. 
de ser considerados estrangeiros, de tal forma estavam afeiçoados ao país.

No artigo, Câmara trata a questão da nacionalização do ensino como desejo de os colonos estudarem nas escolas brasileiras e, principalmente, aprenderem a língua portuguesa, declarando, inclusive, que estes percorriam longas distâncias para ir à escola.

E' êste um dos motivos pelos quais a simples substituição da escola alemã pela brasileira não foi suficiente; a esta última o afluxo tem sido bem maior, mercê do interêsse que despertou e que bem atesta a inclinação brasileira dos colonos locais; e assim se explica o grito constante que ouço naquelas zonas, em minhas recentes viagens: Mais escolas! mais escolas! É que se tornou indispensável substituição da congênere alemã por duas e mesmo mais escolas brasileiras.

Aquí vemos o atestado mais vivo e convincente da mais plena aceitação da mentalidade brasileira (CÂMARA, 1940a, p. 35).

No entanto, Câmara critica a existência dos quistos raciais, dando exemplo de comunidades, como a do Vale do Itajaí, em Santa Catarina, que se mantiveram em total isolamento, e não "produziram elementos úteis à humanidade" (CÂMARA, 1940a, p. 36), ao contrário de outras comunidades que se abriram ao convívio com a sociedade brasileira e "apresentam filhos que se destacam em todos os ramos da nossa atividade; alguns chegaram mesmo a dirigir seu Estado natal" (CÂMARA, 1940a, p. 36).

No geral, são tecidos muitos elogios aos colonos de origem alemã. Percebe-se um esforço em apresentar uma imagem positiva e condescendente do Governo federal, que teria sido forçado a substituir as escolas alemãs pelas brasileiras devido à interferência de agentes de governos estrangeiros no país. 
E’ bom, no entanto, frisar que, nêste particular, o Govêrno do Brasil tem agido apenas com armas espirituais; relegou completamente os meios violentos, e nem ao menos imitou certo país que determinou até a tradução dos nomes dos descendentes de alemães, fáto contra o qual não se insurgem os pangermanistas (CÂMARA, 1940a, p. 41).

O Conselheiro refuta ainda a caracterização dos descendentes de alemães como de nacionalidade alemã. Para Câmara, a nacionalidade legítima destes seria a brasileira. Da mesma forma, repudia a utilização de termos como "luso-brasileiro", "teuto-brasileiro" e "slavo-brasileiro", que apenas geram divisões na sociedade e são de uso desconhecido pelo próprio brasileiro.

Por fim, Câmara defende o monolinguismo do português, ao mesmo tempo em que demonstra tolerância ao uso do idioma do imigrante, quando, na verdade, a própria legislação brasileira da época, conforme já exemplificado, apontava em sentido contrário.

Eis aqui uma verdade que necessita ser proclamada com toda a força dos pulmões:

NÃO EXISTE A TÃO DECANTADA IGNORÂNCIA DA LINGUA PORTUGUESA POR PARTE DOS DESCENDENTES DOS COLONOS ALEMÃES.

E' uma balela de que se querem utilizar os exploradores. O português é a língua usada no Brasil, em todos os seus recantos.

Declara o autor que alguns brasileiros julgam que a língua alemã deve ser exterminada. Não há tal. Ao Brasil interessa sobremaneira que os seus filhos conheçam idiomas estrangeiros; e não por que excluir o alemão, língua usada por um povo que se acha indiscutivelmente entre os vanguardeiros da civilização hodierna (CÂMARA, 1940a, p. 43).

É interessante observar o tom harmonioso utilizado ao longo do 
texto, de forma a se criar a impressão de que o projeto de construção da nação brasileira era realizado em sintonia com os anseios das comunidades de imigrantes.

O segundo artigo é reprodução da palestra apresentada por Câmara, a convite da Associação Brasileira de Educação, a professores de diversas partes do Brasil presentes no curso de férias da Associação. Novamente, o Conselheiro inicia sua fala conferindo a ela legitimidade, uma vez que visitou, por mais de uma ocasião, os núcleos coloniais.

Já na introdução, Câmara é categórico em assinalar que a nacionalização do ensino é apenas um meio para se alcançar o objetivo maior, a assimilação das comunidades de imigrantes, destacando assim o importante papel a ser exercido pela educação dentro do projeto nacionalista do Governo.

Primeiramente, é ressaltada a preocupação com as crianças, que, embora descendentes de estrangeiros, tendo nascido no Brasil, eram, portanto, brasileiros natos. Para Câmara, essas crianças sofriam um processo de "desnacionalização" que precisava ser combatido, e afirmava: "Batizadas com nomes estrangeiros, próprios do torrão natal até para acidentes geográficos, e falando uma língua que não é a nossa, percebia-se como essas crianças se tornavam estrangeiras dentro do próprio Brasil” (CÂMARA, 1940b, p. 239).

Segundo o Conselheiro, instituições ligadas aos países de origem mantinham ingerência sobre as comunidades de imigrantes, agindo na desnacionalização das crianças, por meio da influência de organizações (escolas, associações e igrejas) e do próprio lar. Dessa maneira, foram fechadas escolas e associações estrangeiras e restrita a ação dos sacerdotes. Aonde a lei não chegava, ou seja, nos lares, eram utilizados os próprios filhos de forma a inculcar os valores nacionais.

Não sendo possível a penetração direta no lar, a atuação neste setôr deveria, forçosamente, ser feita de modo 
indireto; tal como modificando a mentalidade dos filhos, e compelindo os pais a certas obrigações para com a nossa língua. Sem dúvida alguma, a mais eficaz seria, fatalmente, a influência exercida pelos próprios filhos, que adquirem uma mentalidade brasileira e aos poucos vão convencendo os seus pais de que a sua pátria não é a de origem dos seus progenitores, e que o nosso estremecido Brasil tem direito aos mesmos carinhos que os seus pais consagram à pátria distante (CÂMARA, 1940b, p. 241-242).

$\mathrm{Na}$ palestra, Câmara também aponta a importância da educação para aqueles que não estão mais em idade escolar, mas que não tiveram a oportunidade de aprender o português, reforçando o caráter fundamental da unidade linguística para o projeto de homogeneização da população brasileira.

Nota-se, nesse segundo artigo de Câmara, o objetivo de suscitar nos professores presentes no curso de férias da Associação a missão patriótica de nacionalização das comunidades de imigrantes por meio da educação.

Por fim, vale destacar o artigo de Ribeiro Couto, membro da Academia Brasileira de Letras, intitulado "Língua nacional e espírito nacional" (COUTO, 1941, p. 788-798). Nele, o autor vai além da ideia de que a educação e, consequentemente, o ensino da língua portuguesa alcançariam, por si só, a assimilação dos imigrantes nos núcleos coloniais do sul do Brasil. Couto utiliza um tom mais rígido ao defender a obrigatoriedade do uso da língua portuguesa, bem como a proibição do uso da língua do imigrante nos espaços públicos.

Da mesma maneira que Câmara, Couto sustenta suas reflexões na visita que realizou às zonas de colonização germânica e italiana no sul do país. O autor cita ainda antropólogos e sociólogos, como Roquette Pinto, Oliveira Vianna e Gilberto Freire, para corroborar seu pensamento, e afirma que parte de suas impressões foi publicada igualmente em entrevista ao Correio da Manhã, com repercussão em outros órgãos de imprensa 
brasileira.

Para Couto, a língua portuguesa representava o alicerce do processo de nacionalização dos núcleos coloniais, contudo, fazia-se essencial a atuação do Estado de forma a impor seu uso real em todas as circunstâncias.

Com efeito, a base da nacionalização (processo muito mais psicológico do que antropológico) será a língua. Ora, segundo observei nas zonas de colonização germânica, o mal não está em que muita gente das povoações rurais não sabe o idioma nacional: $\mathrm{o} \mathrm{mal}$ está em que, nas próprias cidades, esse idioma não é empregado pelos que o sabem (COUTO, 1941, p. 790).

Segundo o autor, os descendentes de alemães não falavam português entre si, vivendo num verdadeiro isolamento cultural. Por mais que utilizassem o idioma nacional na escola, quando de lá saíam tudo se perdia. Couto demonstra até a aceitação do uso do idioma de origem do imigrante, e mesmo da vivência de sua cultura, mas apenas em casa, no ambiente familiar. Em público, a única língua a ser utilizada deveria ser a nacional, para a solidificação de valores comuns e a formação da consciência de um só povo. A associação direta entre idioma e nacionalidade levava ao postulado de que onde não houvesse o entusiasmo a um não haveria ao outro.

Assim, Couto não só sustenta todas as formas de repressão na salvaguarda do projeto nacionalista, mas também cita a fala do próprio presidente Vargas para ratificar seu discurso: “[...] nenhum sacrifício será bastante, nenhuma vigilância será excessiva para a defesa da nossa bandeira, do nosso idioma, das nossas tradições" (COUTO, 1941, p. 794).

Há um claro interesse do autor em demonstrar que a mídia impressa também apoiava a obrigatoriedade do uso do português não apenas nas escolas, mas em todos os âmbitos públicos, como igreja, comércio etc. 
Dessa forma, envolve a sociedade numa missão que até então ficava restrita ao Exército. O artigo ainda exalta a atuação do Estado Novo na campanha nacionalizadora, enquanto enfatiza o perigo, para a unidade nacional, dos quistos raciais.

Para finalizar, o autor reforça os conceitos de homogeneização da população e de monolinguismo, destacando que o sentido de nação está acima dos direitos individuais.

Cada brasileiro tem o direito de orgulhar-se dos seus ascendentes e de manter, dentro de casa, o culto das tradições familiares. Mas tambem, acima dessa liberdade e desse louvável instinto de conservação étnica, está o interesse público, que nos ordena defender os vínculos de uma conciência comum, de uma língua comum, de uma cultura comum (COUTO, 1941, p. 798).

Observa-se que a Revista de Imigração e Colonização deu voz, ao longo dos anos, a autores com percepções diversas acerca do nível de aculturação dos núcleos coloniais bem como de quais seriam as melhores estratégias para se alcançar tal objetivo. No entanto, todos tinham o mesmo propósito, o de legitimar e disseminar o discurso nacionalista do Estado Novo de assimilação das comunidades de imigrantes, principalmente a partir da imposição de políticas linguísticas repressivas.

\section{Considerações Finais}

No pós-Primeira Guerra Mundial, o ideário nacionalista se une ao caráter totalitário de alguns Estados, fomentando nas sociedades os sentimentos de xenofobia e discriminação. No Brasil, com a instauração do Estado Novo, em 1937, o nacionalismo serviu como justificativa para a violação dos direitos linguísticos das comunidades de imigrantes já 
presentes no Brasil, bem como para a restrição do afluxo de novas correntes imigratórias de povos considerados de difícil assimilação.

De um lado, uma ampla legislação foi construída, em 1938 e 1939, dando suporte ao poder coercitivo do Estado. De outro, foram criados dispositivos de convencimento da necessidade das políticas linguísticas repressivas - como a Revista de Imigração e Colonização.

A Revista, porta-voz do projeto nacionalista do Governo Vargas, ratificava e repetia incessantemente seu discurso xenofóbico. O pensamento estampado nos artigos, fossem eles de autoria dos próprios conselheiros fossem de convidados a participar da RIC, reforçava a crença na importância da homogeneização da população brasileira e, principalmente, da assimilação das comunidades de imigrantes. Da mesma forma, propagava o conceito de imigrantes desejáveis, aqueles considerados de fácil assimilação, que poderiam contribuir para a formação de um só povo. A disseminação do monolinguismo baseado na língua portuguesa também teve destaque na Revista, uma vez que a diversidade linguística era considerada uma ameaça ao projeto de construção da Nação.

Conclui-se, assim, que a Revista de Imigração e Colonização atuou como instrumento de divulgação e de legitimação do ideário nacionalista do Estado Novo, bem como de suas políticas linguísticas opressivas em relação às comunidades de imigrantes no Brasil.

BELARMINO, Camila Almeida. Diálogos para construir uma nação: continuidades da questão nacional do pensamento social brasileiro nas páginas da Revista de Imigração e Colonização. 2012. Dissertação (Mestrado em História) - Programa de Pós-Graduação em História, Universidade do Estado do Rio de Janeiro, Rio de Janeiro, 2012.

BRASIL. Decreto-Lei no 406, de 04 de maio de 1938. Dispõe sobre a entrada 
de estrangeiros no território nacional. Rio de Janeiro, DF: Presidência da República, [1938a]. Disponível em: https://www.planalto.gov.br/ccivil_03/ decreto-lei/1937-1946/Del0406impressao.htm. Acesso em: 22 jul. 2020.

. Decreto $n^{\circ} 3.010$, de 30 de agosto de 1938. Regulamenta o decretolei $\mathrm{n}^{\circ} 406$, de 04 de maio de 1938. Rio de Janeiro, DF: Presidência da República, [1938b]. Disponível em: http://www.planalto.gov.br/ccivil_03/ decreto/1930-1949/D3010impressao.htm. Acesso em: 22 jul. 2020.

. Decreto-Lei $n^{\circ} 868$, de 18 de novembro de 1938. Cria, no Ministério da Educação e Saúde, a Comissão Nacional de Ensino Primário. Rio de Janeiro, DF: Presidência da República, [1938c]. Disponível em: $<$ https:// www2.camara.leg.br/legin/fed/declei/1930-1939/decreto-lei-868-18novembro-1938-350829-publicacaooriginal-1-pe.html>. Acesso em: 22 jul. 2020.

. Decreto-Lei $n^{\circ} 3.691$, de 06 de fevereiro de 1939. Aprova o regimento do Conselho de Imigração e Colonização. Rio de Janeiro, DF: Presidência da República, [1939a]. Disponível em: <https://www2.camara.leg.br/ legin/fed/decret/1930-1939/decreto-3691-6-fevereiro-1939-345819publicacaooriginal-1-pe.html>. Acesso em: 22 jul. 2020.

. Decreto-Lei $n^{\circ} 1.545$, de 25 de agosto de 1939. Dispõe sobre a adaptação ao meio nacional dos brasileiros descendentes de estrangeiros. Rio de Janeiro, DF: Presidência da República, [1939b]. Disponível em: <https://www2.camara.leg.br/legin/fed/declei/1930-1939/decreto-lei1545-25-agosto-1939-411654-publicacaooriginal-1-pe.html>. Acesso em: 22 jun. 2020.

CÂMARA, Aristóteles de Lima. Os alemães no sul do Brasil (ponto de vista brasileiro). Revista de Imigração e Colonização, Rio de Janeiro, ano I, n. 1, p. 33-46, jan 1940a.

. A nacionalização do ensino. Revista de Imigração e Colonização, Rio de Janeiro, ano I, n. 2, p. 236-253, abr 1940b. 
CONSELHO, Secretaria do. Primeiro ano de trabalhos do Conselho de Imigração e Colonização. Revista de Imigração e Colonização, Rio de Janeiro, ano I, n. 1, p. 5-19, jan 1940.

. Terceiro ano de trabalhos do Conselho de Imigração e Colonização. Revista de Imigração e Colonização, Rio de Janeiro, ano III, n. 1, p. 10-23, abr 1942.

COOPER, Robert L. La planificación lingüística y el cambio social. Cambridge: Cambridge University Press, 1997.

COUTO, R. Ribeiro. Língua nacional e espírito nacional. Revista de Imigração e Colonização, Rio de Janeiro, ano II, n. 2 e 3, p. 788-798, abr/ jul 1941.

FAUSTO, Boris. Getúlio Vargas: o poder e o sorriso. São Paulo: Companhia das Letras, 2006.

KOIFMAN, Fábio. O imigrante ideal. Rio de Janeiro: Civilização Brasileira, 2012.

MONTEAGUDO, Henrique. A invenção do monolinguismo e da língua nacional. Gragoatá, Niterói, n. 32, p. 43-54, $1^{\circ}$ semestre 2012.

MUNIZ, João Carlos. Apresentação. Revista de Imigração e Colonização, Rio de Janeiro, ano I, n. 1. p. 3-4, jan 1940.

QUEIROZ, Thaíla Guimarães. As restrições imigratórias na Revista de Imigração e Colonização (1940-1945). Recôncavo: Revista de História da UNIABEU, [s. l.], v. 3, n. 5, p. 136-150, jul/dez 2013.

REVISTA DE IMIGRAÇÃO E COLONIZAÇÃO. Rio de Janeiro: Conselho de Imigração e Colonização, 1940-1945.

The nationalist monolingualism of the Estado Novo (New State) in the pages of the immigration and colonization magazine

Abstract: This article analyzes the contribution of the Immigration and 
Colonization Magazine to the actions developed by the Getulio Vargas Government during the Estado Novo (New State) (1937-1945) in order to disseminate and legitimize nationalism in Brazil. In this context, the defense of monolingualism based on the Portuguese language was understood as essential not only for the union of the Brazilian population but also for the assimilation of immigrant communities. Thus, besides the authoritarian policies performed by Vargas Government through laws that restrained the use and the teaching of foreign languages, several other linguistic policies were developed using the State apparatus, with the objective of building the national identity, like the Immigration and Colonization Magazine.

Keywords: Linguistic Policies. Nationalism. Immigration and Colonization Magazine.

\section{Recebido em: 18/08/2020}

Aceito em: 23/06/2021 